\title{
Factors affecting maritime pilots' health and well-being: a systematic review
}

\author{
Luana C. Main ${ }^{1}$, Timothy P. Chambers ${ }^{2}$ \\ ${ }^{1}$ Centre for Physical Activity and Nutrition Research, Deakin University, Australia \\ ${ }^{2}$ School of Psychological Sciences, Australian College of Applied Psychology, Melbourne, Australia
}

\begin{abstract}
Background: Maritime pilotage is a demanding occupation where pilots are required to perform complex procedures in sometimes unfamiliar working environments. These psychological stressors, in addition to the physical demands associated with the role (e.g., reduced sleep, boarding, and departing vessels), may over time have a damaging effect on pilots' physical and mental health. Therefore the aim of this paper was to systematically review the existing literature on maritime pilots' health and well-being.

Materials and methods: The databases academic search complete, MEDLINE and MEDLINE complete, PsycINFO, PsycARTICLES, PubMed, and ScienceDirect were searched from the earliest available record until 1 May 2015. From an initial pool of 167 manuscripts retrieved, only 18 were peer-reviewed original research and discussed topics associated with maritime pilots' health and well-being.

Results: In total, 29 factors associated with maritime pilot health and well-being were identified. These were loosely categorised into physical $(n=14)$, psychosocial $(n=8)$, and workplace issues $(n=7)$. The most commonly investigated factors were blood pressure or heart rate, sleep or fatigue, smoking and alcohol consumption, perceived stress, and shift duration or cycle.

Conclusions: Findings from the review suggest that the prevention of cardiovascular diseases and associated cardio-metabolic risk factors seems to be of paramount importance, with ample evidence indicating that modern-day pilots present as being overweight or obese. What remains unknown is whether these physical factors are associated with variations in psychosocial functioning. Therefore, it is recommended that future pilotage investigations adopt a multidisciplinary approach to better quantify the impact of maritime pilotage on long-term health and well-being.
\end{abstract}

(Int Marit Health 2015; 66, 4: 220-232)

Key words: health, well-being, maritime, pilot, stress, fatigue, review

\section{INTRODUCTION}

The maritime industry is one of the oldest in history, facilitating approximately $90 \%$ of the world's trade via the international shipping industry. In Australia, for example, $10 \%$ of the world's trade is managed across 70 ports, in one of the largest exclusive economic zones and world heritage coastlines [1]. Central to the survival of these industries are the seafarers who work long shifts, often in difficult conditions $[2,3]$. One role that is critical to the maritime industry is the maritime pilot who operates at the land-sea interface [4]. Typically, maritime pilots are responsible for the safe navigation of vessels through restricted and challenging waterways [5], often operating in isolation, and completing long shifts in sometimes unfamiliar working environments. To this end, maritime pilots are often responsible for ensuring the continuity of a nation's trading agreements, in addition to preserving sensitive environmental regions. Accordingly, maritime pilotage is recognised as a stressful and autonomous occupation that requires extended periods of attention, and moderate physical fitness [6].

A closer examination of the role suggests that maritime pilotage can impact the psychophysiological health and 
Table 1. Database search strategy

$\begin{array}{ll}\text { Search } 1 & \text { In title or abstract or subject heading: "Maritime Pilot*" OR "Sea Pilot*" OR "Ship Pilot*" OR "Port Pilot*" OR } \\ \text { "Coastal Pilot*" OR "Marine Pilot*" OR "Off-shore Pilot*" } & \\ \text { Search } 2 & \text { In title Pilot* (Ti) AND "maritime" in title or abstract or subject heading } \\ \text { Search } 3 & \text { A manual search including: "pilot*" AND "river" OR "canal” etc. }\end{array}$

well-being of the individual, resulting in sleep problems [7], cognitive disturbances and attentional deficiencies [4], and physical harm through injury [8]. Historically, data indicate that maritime pilots are at a high risk for cardiovascular diseases (CVD), the associated cardio-metabolic risk factors, and mental health problems [9]. Often, prevalence rates for CVD far exceed those reported in normative population data [9]. Recent industry reports suggest that the maritime industry is growing at an unprecedented rate, resulting in increased commercial pressures and demands on the various individuals working in this context $[5,10]$. The subsequent increase in the number of reported accidents and incidents in the last 10 years is a possible consequence of this commercial growth [11]. For maritime pilots, the exponential growth of the industry manifests in longer shift durations and shorter turn-a-round times at port. Yet despite the industry's growth, research pertaining to understanding the health and well-being of maritime pilots in this evolving environment has not been a priority, with greater attention paid to other roles such as seafarers [12] and coast guard officers $[13,14]$. The lack of empirical research on maritime pilots since the seminal work of Cook and Shipley [6] suggests that consolidation of the available evidence on pilot health and well-being is well-overdue.

Subjective well-being refers to the self-evaluation of a collection of diverse phenomena, including judgements about life satisfaction, work satisfaction, feelings, mood, and emotions [15]. There is an emerging body of evidence that is based on diverse methodologies which state that subjective well-being directly affects physical health. The converging evidence demonstrates that subjective well-being and physical health are inextricably linked [15]. These interactions appear evident across a number of physical (e.g., vitality, global health, sleep quality, and CVD) and psychosocial factors (e.g., job performance and satisfaction, marital status, and psychological dysfunction) related to health and well-being [16]. Therefore, the psychophysical relationship between factors of health and well-being may be critical in explaining the current state of maritime pilots. While much evidence exists on the physical and psychological health and well-being of seafarers $[17,18]$, there seems a lack of such knowledge about maritime pilots. What is required is a comprehensive appraisal of the current knowledge, with a view to guide future inquiry. Therefore, the aim of this systematic review was to examine the available empirical literature and assess the current knowledge pertaining to maritime pilots' health and well-being.

\section{MATERIALS AND METHODS}

The study was designed as per the PRISMA guidelines for systematic reviews and meta-analyses [19]. An electronic search was conducted using the following databases: academic search complete, MEDLINE, MEDLINE complete, PsycINFO, PsycARTICLES, PubMed, and ScienceDirect. Three search strategies were adopted and are outlined in Table 1. Databases were searched from the earliest available record up to 1 May 2015, with results limited to human and English language; relevant article links were also explored. Only articles which were peer-reviewed, original research, and discussed topics associated with maritime pilots' health were included. Articles to do with international law, risk management or assessment, and various technological advances as determined from the title and or abstract were excluded from the final selection. The selection of studies is detailed in Figure 1.

\section{RESULTS}

From the initial 167 articles retrieved from database searches, only 57 were actually about 'maritime pilots'. Of these, 34 were excluded as duplicates. A manual search yielded an additional 6 new articles which were included in the penultimate step $(n=29)$. Eleven manuscripts were excluded because they were not about topics relating to maritime pilots health and well-being; therefore a final 18 studies were included in the analysis. Following a detailed examination of each article the aim, measures and methodology of each study were summarised and are presented in Table 2. Emerging from this process were 29 factors associated with maritime pilot health and well-being that were further investigated. These were loosely categorised into physical ( $n=14)$, psychosocial $(n=8)$, and workplace issues $(n=7)$. These factors, and the frequency of which they were reported, are documented in Table 3.

\section{DISCUSSION}

The aim of this review was to employ the PRISMA guidelines to systematically appraise the available empirical evidence on maritime pilot health and well-being. In doing so, the manuscript aimed to provide a consolidated account of the current knowledge on pilot health and well-being with 


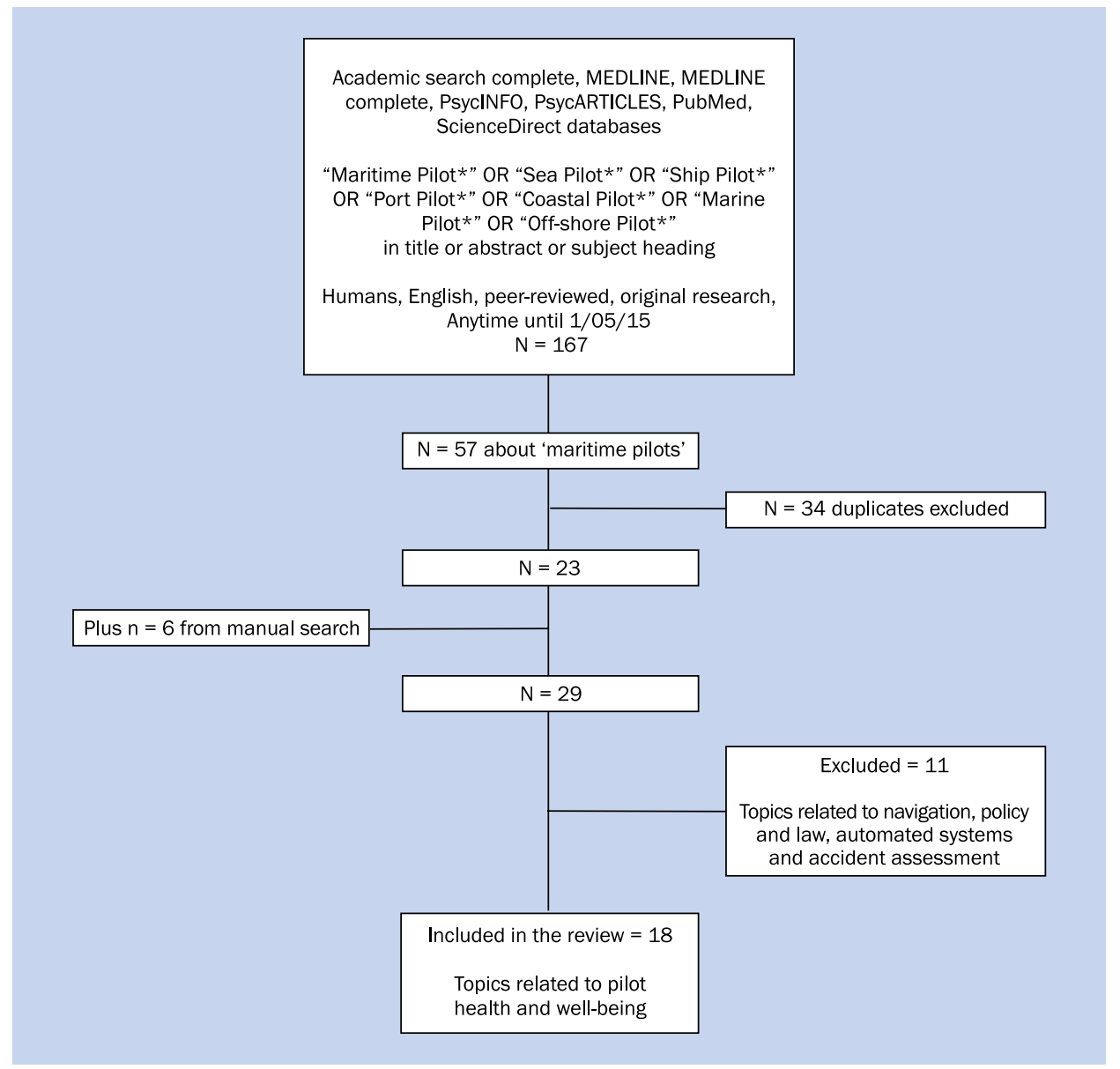

Figure 1. Selection of studies flow chart

a view to inform future research endeavours. The findings revealed that a wide array of methods and measures were employed to assess maritime pilot health and well-being, with a clear preference for utilising physiological measures (e.g., heart rate [HR], fatigue) to document the pilot state. Equally evident was the lack of attention on psychological well-being, specifically the prevalence on psychological dysfunction (e.g., anxiety, depression) among pilots.

In reviewing the 18 empirical manuscripts, it was also apparent that two of the articles captured did not actually meet the aim of the current review [20,21]. For example, while the Kim et al. [20] study included pilots as part of their sample, they failed to detail their pilot demographics separate to the maritime officers also recruited as participants. Rather, pilots were referred to in the context of a control group in an experimental simulation task examining the effect of alcohol on simulated ship handing [20]. Likewise, Van Damme [21] also failed to provide a descriptive account of the participants interviewed in his examination of pilot post-traumatic stress disorder. Rather, the article provided an overview of the disorder, and recommendations for possible treatment. Therefore, while both these studies met the inclusion criteria, they will not be discussed any further. Hence, what follows is a linear discussion of the various factors related to maritime pilot health and well-being. It is recognised that many of these factors co-exist; however, the authors have chosen to present the findings in such a manner to better illustrate the unique contribution each makes to the literature. Consideration for the multidimensional nature of maritime pilot health and well-being will be addressed in the final section.

\section{FACTORS ASSOCIATED WITH PHYSICAL HEALTH}

A total of 14 physical health factors were identified in the reviewed articles, including factors such as the presence of injury or illness, and response to physical tests (e.g., exercise, galvanic skin response). Of these, the most common were blood pressure (BP) or HR, smoking, alcohol consumption, sleep or fatigue, and CVD. In several cases, factors such as smoking and alcohol consumption were discussed in the context of CVD risk factors.

$\mathrm{BP}$ and HR were the most frequently cited physiological health and well-being factors. Two studies reported evidence of variability in $\mathrm{HR}$ or $\mathrm{BP}$, either during or following pilotage, 
Table 2. Summary of articles reviewed presented chronologically by publication date

\begin{tabular}{|c|c|c|c|c|c|c|}
\hline Reference & $\begin{array}{l}\text { Number of } \\
\text { participants }\end{array}$ & Type of pilots & $\begin{array}{l}\text { Mean } \\
\text { age } \pm \text { SD }\end{array}$ & Study purpose & Method & Measures \\
\hline $\begin{array}{l}\text { Chambers } \\
\text { and Main } \\
(2015)\end{array}$ & 50 & $\begin{array}{l}\text { Australian } \\
\text { maritime pilots }\end{array}$ & $\begin{array}{l}51.42 \pm \\
\pm 9.81 y\end{array}$ & $\begin{array}{l}\text { Comparison of fatigue } \\
\text { and coping strategies } \\
\text { between maritime and } \\
\text { aviation pilots }\end{array}$ & $\begin{array}{l}\text { Online } \\
\text { questionnaire }\end{array}$ & $\begin{array}{l}\text { Symptoms of fatigue } \\
\text { checklist, coping strate- } \\
\text { gies checklist and vitality } \\
\text { scale }\end{array}$ \\
\hline $\begin{array}{l}\text { Kaya Ozbag } \\
\text { and Ceyhun } \\
(2014)\end{array}$ & 100 & $\begin{array}{l}\text { Turkish marine } \\
\text { pilots }\end{array}$ & $\mathrm{N} / \mathrm{A}$ & $\begin{array}{l}\text { Investigate the media- } \\
\text { ting effect of job satis- } \\
\text { faction on work-family } \\
\text { conflict }\end{array}$ & Questionnaire & $\begin{array}{l}\text { Work-family conflict, job } \\
\text { satisfaction, and turno- } \\
\text { ver intentions }\end{array}$ \\
\hline $\begin{array}{l}\text { Rutledge } \\
\text { (2014) }\end{array}$ & $\begin{array}{l}44 \text { in } 1988 ; \\
27 \text { in } 2012\end{array}$ & $\begin{array}{l}\text { Scottish River } \\
\text { Forth pilots }\end{array}$ & $\begin{array}{l}53 \text { y in } \\
1988 \\
50 y \\
\text { in } 2012\end{array}$ & $\begin{array}{l}\text { Comparison of maritime } \\
\text { pilotage medical exami- } \\
\text { nation data from } 1988 \\
\text { and } 2012\end{array}$ & $\begin{array}{l}\text { Comparison of } \\
\text { data from medical } \\
\text { examinations }\end{array}$ & $\begin{array}{l}\text { Medical examination } \\
\text { records }\end{array}$ \\
\hline $\begin{array}{l}\text { Scovill et al. } \\
(2012)\end{array}$ & $\begin{array}{l}388 \text { mariners } \\
\text { (specific num- } \\
\text { ber of pilots not } \\
\text { disclosed) }\end{array}$ & $\begin{array}{l}\text { Unites States } \\
\text { inland waterway } \\
\text { merchant marine } \\
\text { captains and } \\
\text { pilots }\end{array}$ & $44 y$ & $\begin{array}{l}\text { Cross sectional study of } \\
\text { mariner health charac- } \\
\text { teristics }\end{array}$ & $\begin{array}{l}\text { Comparison of } \\
\text { data from the } \\
\text { USCG physical } \\
\text { assessment from } \\
2003-2010\end{array}$ & $\begin{array}{l}\text { Treadmill stress test } \\
\text { (Standard Bruce Test } \\
\text { Protocol) } \\
\text { USCG medical exam }\end{array}$ \\
\hline $\begin{array}{l}\text { Ferguson et } \\
\text { al. (2008) }\end{array}$ & $\begin{array}{l}17 \text { (1/3 of the } \\
\text { population) }\end{array}$ & $\begin{array}{l}\text { Australian } \\
\text { coastal pilots } \\
\text { (Barrier reef) }\end{array}$ & $\begin{array}{l}55.9 \pm \\
\pm 8.0 y\end{array}$ & $\begin{array}{l}\text { Examination of the im- } \\
\text { pact of brief, unschedu- } \\
\text { led naps during work } \\
\text { shifts for coastal pilots }\end{array}$ & $\begin{array}{l}\text { Field study of } \\
\text { sleepiness }\end{array}$ & $\begin{array}{l}\text { Self-report sleep and } \\
\text { work diary } \\
\text { Palm PVT task to record } \\
\text { alertness while at work } \\
\text { aboard ships }\end{array}$ \\
\hline $\begin{array}{l}\text { Andresen et } \\
\text { al. (2007) }\end{array}$ & $\begin{array}{l}434(26.8 \% \\
\text { response rate) }\end{array}$ & $\begin{array}{l}\text { European } \\
\text { maritime pilots }\end{array}$ & $\mathrm{N} / \mathrm{A}$ & $\begin{array}{l}\text { Examination of job sa- } \\
\text { tisfaction for European } \\
\text { maritime pilots }\end{array}$ & Questionnaire & $\begin{array}{l}\text { Relationship between } \\
\text { working unusual hours, } \\
\text { physical strain and job } \\
\text { satisfaction }\end{array}$ \\
\hline $\begin{array}{l}\text { Darbra et al. } \\
(2007)\end{array}$ & 77 & $\begin{array}{l}\text { Australian and } \\
\text { New Zealand } \\
\text { pilots }\end{array}$ & $50 y$ & $\begin{array}{l}\text { Cross sectional study } \\
\text { of safety culture and } \\
\text { hazard risk perception } \\
\text { of maritime pilots }\end{array}$ & $\begin{array}{l}\text { Interviews and } \\
\text { questionnaire }\end{array}$ & $\begin{array}{l}\text { Safety culture and } \\
\text { hazard risk perception }\end{array}$ \\
\hline $\begin{array}{l}\text { Griffiths and } \\
\text { Ellis (2007) }\end{array}$ & 1 & European pilots & $37 y$ & $\begin{array}{l}\text { Case study of visual } \\
\text { conversion disorder }\end{array}$ & Case study & Medical records \\
\hline $\begin{array}{l}\text { Kim et al. } \\
(2007)\end{array}$ & $\begin{array}{l}118 \text { officers } \\
\text { Pilots }=N / A\end{array}$ & $\begin{array}{l}\text { Officers and } \\
\text { pilots }\end{array}$ & $\mathrm{N} / \mathrm{A}$ & $\begin{array}{l}\text { Assess the drinking sta- } \\
\text { tus of maritime officers, } \\
\text { and examine the effect } \\
\text { of alcohol on simulated } \\
\text { ship handing }\end{array}$ & $\begin{array}{l}\text { Questionnaire } \\
\text { and simulated } \\
\text { task }\end{array}$ & $\begin{array}{l}\text { Survey of current drink- } \\
\text { ing habits and education } \\
\text { Simulated navigational } \\
\text { ability }\end{array}$ \\
\hline $\begin{array}{l}\text { Meere et al. } \\
(2005)\end{array}$ & 130 & Flemish pilots & $\begin{array}{l}47.5 \pm \\
\pm 7.7 y\end{array}$ & $\begin{array}{l}\text { Cross sectional study of } \\
\text { occupational accidents } \\
\text { and injuries sustained } \\
\text { by maritime pilots }\end{array}$ & Questionnaire & $\begin{array}{l}\text { Body mass index; pilo- } \\
\text { tage history; number of } \\
\text { reported accidents; } \\
\text { various measures of } \\
\text { health; safety culture } \\
\text { and the organisation }\end{array}$ \\
\hline $\begin{array}{l}\text { Van Damme } \\
\text { (2003) }\end{array}$ & $\mathrm{N} / \mathrm{A}$ & Maritime pilots & $\mathrm{N} / \mathrm{A}$ & $\begin{array}{l}\text { Assess the prevalence } \\
\text { of PTSD in maritime } \\
\text { pilots to aid prevention } \\
\text { of PTSD }\end{array}$ & Interviews & $\mathrm{N} / \mathrm{A}$ \\
\hline $\begin{array}{l}\text { Saarni et al. } \\
(1996 a)\end{array}$ & 135 & Finnish sea pilots & $51 y$ & $\begin{array}{l}\text { Examine the cardio- } \\
\text { vascular risk factors } \\
\text { for Finnish sea pilots }\end{array}$ & Laboratory study & $\begin{array}{l}\text { Bicycle-exercise test, } \\
\text { cholesterol, blood } \\
\text { pressure, ECG }\end{array}$ \\
\hline $\begin{array}{l}\text { Saarni et al. } \\
(1996 b)\end{array}$ & 262 & Finnish sea pilots & $\mathrm{N} / \mathrm{A}$ & $\begin{array}{l}\text { Retrospectively examine } \\
\text { of the mortality rate of } \\
\text { Finnish sea pilots }\end{array}$ & $\begin{array}{l}\text { Examination of } \\
\text { medical data }\end{array}$ & $\begin{array}{l}\text { Medical and death } \\
\text { records }\end{array}$ \\
\hline
\end{tabular}


Table 2. cont. Summary of articles reviewed presented chronologically by publication date

\begin{tabular}{|c|c|c|c|c|c|c|}
\hline Reference & $\begin{array}{l}\text { Number of } \\
\text { participants }\end{array}$ & Type of pilots & $\begin{array}{l}\text { Mean } \\
\text { age } \pm \text { SD }\end{array}$ & Study purpose & Method & Measures \\
\hline $\begin{array}{l}\text { Sparks } \\
(1992)\end{array}$ & 93 & $\begin{array}{l}\text { Masters, mates, } \\
\text { and pilots }\end{array}$ & $44 y$ & $\begin{array}{l}\text { Survey of health, social, } \\
\text { and performance indi- } \\
\text { ces related to shift work }\end{array}$ & Questionnaire & $\begin{array}{l}\text { Demographics, personal } \\
\text { habits, lifestyle, job, } \\
\text { health, psychological } \\
\text { status, sleep and eating } \\
\text { patterns, and shift } \\
\text { schedule }\end{array}$ \\
\hline $\begin{array}{l}\text { Cook and } \\
\text { Cashman } \\
(1982)\end{array}$ & 8 & $\begin{array}{l}\text { United Kingdom } \\
\text { ship pilots }\end{array}$ & $\mathrm{N} / \mathrm{A}$ & $\begin{array}{l}\text { Field study of stress } \\
\text { and physical health } \\
\text { during pilotage }\end{array}$ & $\begin{array}{l}\text { Field study of } \\
\text { stress and } \\
\text { physical health }\end{array}$ & $\begin{array}{l}\text { Stress and ectopic beats } \\
\text { (ECG); Eysenck personality } \\
\text { inventory } \\
\text { Pilotage workload } \\
\text { (e.g., shift duration) }\end{array}$ \\
\hline $\begin{array}{l}\text { Cook and } \\
\text { Shipley } \\
(1980)\end{array}$ & 7 & $\begin{array}{l}\text { United Kingdom } \\
\text { ship pilots }\end{array}$ & $40-50 y$ & $\begin{array}{l}\text { Field study of pilotage } \\
\text { health during working } \\
\text { hours }\end{array}$ & $\begin{array}{l}\text { Field study of } \\
\text { fatigue }\end{array}$ & $\begin{array}{l}\text { Self-reported questionna- } \\
\text { ire on tension, alertness, } \\
\text { and freshness; clinical } \\
\text { thermometers for tempe- } \\
\text { rature assessment; ECG; } \\
\text { reaction time; galvanic } \\
\text { skin response }\end{array}$ \\
\hline $\begin{array}{l}\text { Shipley and } \\
\text { Cook } \\
(1980)\end{array}$ & $\begin{array}{l}150 \text { diary study; } \\
55 \text { question- } \\
\text { naire }\end{array}$ & $\begin{array}{l}\text { United Kingdom } \\
\text { ship pilots }\end{array}$ & $\begin{array}{l}46.5 \pm \\
\pm 8.6 y\end{array}$ & $\begin{array}{l}\text { Cross sectional study } \\
\text { of working scheduling } \\
\text { problems and social } \\
\text { consequences related } \\
\text { to maritime pilotage }\end{array}$ & $\begin{array}{l}\text { Interviews, } \\
\text { questionnaires, } \\
\text { and diary surveys }\end{array}$ & $\begin{array}{l}\text { Work scheduling pro- } \\
\text { blems and social con- } \\
\text { sequences; duty times } \\
\text { and time off; organisa- } \\
\text { tional work-scheduling } \\
\text { systems; job satisfaction } \\
\text { and job fit; sleep pro- } \\
\text { blems; marital satisfac- } \\
\text { tion (personal lives) }\end{array}$ \\
\hline $\begin{array}{l}\text { Zorn et al. } \\
(1977)\end{array}$ & 5 & $\begin{array}{l}\text { German sea } \\
\text { pilots }\end{array}$ & $\mathrm{N} / \mathrm{A}$ & $\begin{array}{l}\text { Comparison of mortality } \\
\text { rates associated with } \\
\text { ischaemic heart disease }\end{array}$ & $\begin{array}{l}\text { Urine analysis for } \\
\text { catecholamines }\end{array}$ & $\begin{array}{l}\text { Ischaemic heart disease } \\
\text { and work stress }\end{array}$ \\
\hline
\end{tabular}

with findings revealing that HR varied across pilotage passages [6], and peaked when pilots were performing stressful pilotage tasks [6, 22]. Further results indicated that HR irregularities were more frequent during pilotage compared to rest [22], and that HR returned to baseline during extended periods of pilot inactivity [6]. The remaining investigations that cited $\mathrm{HR}$ or $\mathrm{BP}$ as a physical factor of pilot health either reported medical screening records [23-27], or treatment of high BP [8]. These investigations revealed approximately $50 \%$ of pilots suffered from high BP [23, 24], with $25 \%$ requiring medication to alleviate the illness [8]. In sum, these findings suggest that pilotage is a stressful occupation, whereby pilots exhibit stress responses when undertaking specific occupational tasks that are unique to their role (e.g., berthing). Moreover, a high percentage of pilots suffer from poor health outcomes.

While these results provide a snapshot of the pilot population, there are two critical limitations associated with this collective evidence.

First, much of the reported field data is dated and does not consider the impact of the contemporary demands of the maritime industry, such as dealing with the increased size of modern vessels and shorter turn-around times [10].

Second, much of the evidence relies upon medical screening data, and not field assessment of physical health. Utilising existing medical records to determine the impact of pilotage on physical health is also problematic as the screening is often conducted as part of the pre-employment check, and typically fills a cultural, not occupational need [27]. While subsequent medical checks are often conducted on pilots, these medical exams have been criticised as failing to prevent health-related occupational risks [27]. Given medical screenings typically occur before the pilot commences work, and that the testing is typically not performed under work conditions, these data do not reflect how pilots respond to workplace stressors, in situ. Therefore longitudinal, multidisciplinary research that holistically captures the psychophysical responses to pilotage in occupational contexts is required.

\section{Fatigue}

Another commonly cited physical factor of health and well-being for pilots were sleep issues and fatigue. Only one 
Table 3. Various factors associated with maritime pilot health and well-being

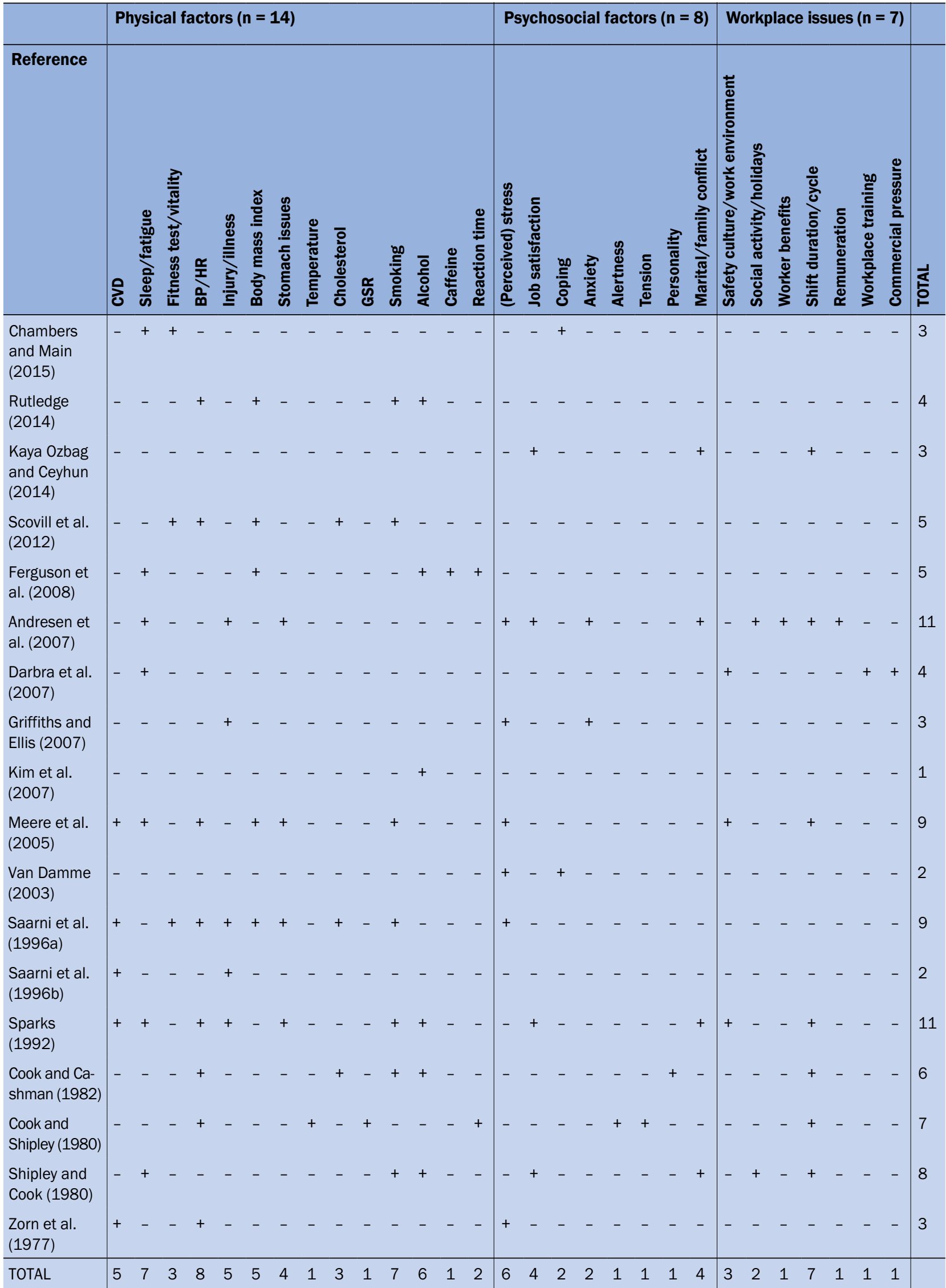

(+) indicates factor was or (-) was not investigated in a manuscript; BP - blood pressure; CVD - cardiovascular diseases; GSR - galvanic skin response; HR - heart rate 
investigation measured sleep during pilotage, with findings revealing that Australian Barrier Reef pilots averaged $1.4 \mathrm{~h}$ of sleep during an average shift length of $39.5 \mathrm{~h}$ [7]). Two investigations also examined psychomotor performance to reliably measure on-shift fatigue and vigilance, with neither study finding a difference in performance as a function of fatigue [6, 7]. However, Cook and Shipley [6] did reveal a severe drop in self-reported alertness following the pilotage passage, and speculated that the drop may have been even more dramatic if not for the existing maritime culture (i.e. pilots typically avoid showing weakness). Three possible explanations are provided to interpret the findings: 1 ) that pilots took naps at appropriate times to mitigate fatigue [7], 2) that pilots relied on an effort of will or additional resources to complete the measures [6], and 3) that a practice effect may have occurred on the psychomotor task [6].

Of the remaining studies that investigated fatigue, all relied on self-report measures to assess fatigue $[4,5,8$, $26,28,29]$. Results from these studies revealed that as pilots became more fatigued, they reported greater cognitive dysfunction (e.g., lost concentration), emotional disturbance (e.g., became grouchy or irritable), physical effects (e.g., experienced a decrease in energy), and sleepiness (e.g., felt sleepy [3]). Moreover, self-reported fatigue scores at the end of a coastal pilotage shift were significantly higher compared to the start of the passage [7], and in another instance, approximately a third of pilots indicated that they were unable to catch up on lost sleep [29]. In terms of managing fatigue, only one study reported on fatigue risk management systems employed across Australian ports [5]. Their findings revealed that a variety of risk management systems were used, and that various commercial pressures often resulted in a lack of adherence to fatigue management protocol (e.g., managers failed to adequately inspect the fatigue risk management system data).

Collectively, these results suggest that maritime pilots often experience fatigue as a consequence of the role (e.g., long shift, challenging tasks), a finding that is consistent with other seafarer [17] and industry contexts [30]. One apparent difference between pilots and other seafarers that may contribute to fatigue is the working environment. Compared to other seafarers, who spend considerable amounts of time aboard the same vessel, pilots move between vessels considerably more frequently. These transitional adjustments may in turn contribute to overall fatigue; the continual movement between vessels, and associated environmental unfamiliarity, may result in accumulated fatigue. While untested, this hypothesis may explain experiential differences in fatigue of maritime personnel.

In reviewing the maritime pilotage literature on fatigue, three main conclusions emerged. First, regardless of how fatigued the pilots perceived themselves, they seemingly maintained adequate vigilance across the duration of a shift. In other words, the evidence suggested that the objective measures of fatigue failed to identify any differences whereas the subjective self-report measures were able to detect changes in fatigue. The implication of this finding is substantial, as it highlights the need for future research to incorporate self-report measures in the assessment of pilotage fatigue.

Second, there was a lack of standardised measurement tools utilised by researchers to assess fatigue. At present, there are a number of valid and reliable self-report measures that provide an accurate account of occupational sleepiness and fatigue (e.g., Epworth Sleepiness Scale [31], Pittsburgh Sleep Quality Index [32]). Future research in this context should utilise these measures to allow for comparisons within, and between industries.

Third, the review highlighted an absence of evidence on fatigue risk management systems in pilotage. With the exception of Darbra et al. [5], little evidence regarding the use and effectiveness of fatigue risk management systems was available. Given the variety of fatigue risk management systems in use, and the extensive research on fatigue management in other fields [33], it seems necessary to compare these systems and assess their effectiveness in monitoring and managing maritime pilot fatigue.

\section{Body mass index}

Another frequently cited physical health factor was body mass index (BMI). Only one field study reported the BMI of pilots, where it was noted that the average pilot was overweight [7]. Other investigations again relied on medical records to determine $\mathrm{BMI}$, with results revealing that between 53\% [8] and $64 \%$ [24] of participants were classified as overweight or obese. Furthermore, the percentage of overweight and obese pilots had risen from $45 \%$ to $67 \%$ in the last 20 years [23]. These data are slightly higher than comparative normative data that revealed in 2011 42\% of adult males were overweight [34]. Only 2 investigations attempted to record diet, noting that for $61 \%$ of pilots work interfered with eating habits [29], and $40 \%$ were dissatisfied with their eating patterns [24]. However, these findings are dated and do not reflect the increasing global trend for fast foods and ever changing diets. Therefore, these data are concerning, particularly when considering the challenging nature of maritime pilotage (e.g., climbing a pilot ladder), and give rise to three possible conclusions.

First, given the nature of the pilotage role, particularly the long shifts on board vessels, a more detailed exploration of pilot eating habits is warranted to investigate whether high caloric snack foods and or caffeinated beverages are being consumed in the absence of regular meals.

Second, the lack of investigation on the impact of BMI on pilots' capacity to fulfil the physical requirements of the 
role requires further attention, as there may be unknown occupational health and safety implications.

Third, the lack of evidence on interventions aimed at reducing pilot $\mathrm{BMI}$ also requires amending.

\section{Cardiovascular disease and related issues}

The most significant health outcome cited in the reviewed literature was CVD, with early reports revealing that cardiac mortality risk was significantly higher for maritime pilots compared to the general population [9]. Complementary findings indicated that the maritime pilot mortality rate, as a consequence of CVD and ischaemic heart disease, was slightly higher than normative populations in Finland, England, and Germany [35]. Other reviewed articles [8, 24, 26] investigated several CVD risk factors, including smoking, alcohol consumption, and physical activity or fitness and reported some alarming findings. For example, $45 \%$ of mariners, including pilots, had combined cholesterol categorised as borderline high or high; $50 \%$ of pilots recorded very poor fitness score, with a further $21 \%$ reporting poor fitness [24]. Elsewhere, it was reported that $52 \%$ of participants consumed alcohol on work days [26]. The evidence regarding smoking was mixed across the studies. For example, Zorn et al. [9] reported that $80 \%$ of pilots were smokers, whereas Shipley and Cook [29], and Scovill et al. [24] noted that 44\% and $41 \%$ of their respective samples smoked. In contrast to these reports, Meere et al. [8] reported that nearly $85 \%$ of their pilot sample did not smoke, and Rutledge [23] noted that the percentage of pilots who smoked had dropped from $41 \%$ to $7 \%$ in the last 20 years, suggesting that in Europe, the number of pilots who smoke may be on the decline. Nevertheless, despite these encouraging findings regarding a decline in smoking, the evidence suggests that maritime pilots are a CVD at-risk working population.

\section{Conclusions on physical health factors}

These combined data on maritime pilot health support the notion that pilots are at a high risk of developing chronic disease, particularly chronic heart disease. Moreover, these data suggest that pilotage is a stressful occupation. While these findings imply that pilots are susceptible to a number of physical health issues, several limitations were identified.

First, much of the available field data is dated, and relied upon small sample sizes, thereby restricting the generalisability of these findings to contemporary pilots. While larger sample sizes may attract more robust findings, the feasibility of recruiting larger sample sizes may be limited.

Second, recent increases in ship size and commercial demands (e.g., short turn-around times) may impact pilot health [11]. For example, the increasing size of ships may place additional demands on pilots with respect to accessing the bridge. If modern pilots are part of an ageing population, are unfit, are required to carry personal protective equipment on each passage, and possess a number of CVD risk factors, it is imperative that future research examine the physiological impact of performing pilotage. It remains unknown whether any combination of these factors negatively impacts on pilot health.

Third, while the current evidence suggests that maritime pilotage is a stressful occupation, no evidence indicated whether physical health (i.e., poor health) impacted upon actual pilotage performance. Therefore, in light of the aforementioned points, it is crucial that investigations of maritime health utilise multidisciplinary approaches to ascertain how health may impact occupational demands (e.g., utilising simulators to test the psychophysical relationships between health and pilotage performance). Finally, there was a lack of evidence related to improving the physical health of maritime pilots (e.g., health interventions or initiatives). The lack of intervention research aimed at improving pilots' current physical state is alarming, given the inherent risks associated with the role (e.g., potential for widespread environmental disasters), and pilots' potentially dire state of health as outlined in the reviewed literature. Research in other specialised occupations (e.g., aviation, medicine) has attempted to design intervention protocols to tackle some of the presenting issues (e.g., improve diet, and reduce fatigue) experienced by workers, including seafarers $[36,37]$ and aviation pilots [38]. Therefore, intervention investigations are essential to provide crucial evidence that enables pilots to function optimally both on and off-shift.

\section{FACTORS ASSOCIATED WITH WELL-BEING}

In examining the manuscripts for psychosocial factors of pilot well-being, it was apparent that less attention was paid to these factors, compared to physical health factors. Nevertheless, a total of 8 psychosocial factors of pilot well-being were identified in the reviewed manuscripts. Of all the factors identified in the review, the most frequently reported were perceived stress, job satisfaction, and marital or family conflict.

\section{Perceived stress}

A total of 6 studies investigated the perceived stress of maritime pilotage. Results revealed that the vast majority of European pilots reported work stress as the main cause of many health problems, including fatigue and insomnia [28]. When prompted, nearly $30 \%$ of these pilots attributed these issues to working at night, and a further $21 \%$ attributed the outcomes to variable weather [28]. Elsewhere, pilots reported experiencing high levels of stress [8], which was supported by physiological data [9] that revealed significant elevations in catecholamine levels from pre- to post-pilotage shift. As testament to the magnitude of stress associated with pilotage (i.e., the impact of stress on performance), 
a maritime pilot case study revealed how psychological stress manifested as a visual impairment for a harbour pilot [39]. The outcome of this pilot's stress was a reduction in his performance (e.g., vessel grounding) and ultimately loss of life (i.e., through suicide). Collectively, these multidisciplinary findings provide support for the notion that pilotage is a stressful occupation, with challenges that are seemingly unique to the role (e.g., berthing vessels).

\section{Job satisfaction}

Four of the reviewed articles investigated job satisfaction. While some of the evidence suggested that pilots were satisfied in their roles [26, 29, 40], a number of issues related to job dissatisfaction were identified for many pilots. These issues included the long and unsocial work hours (e.g., night-shift, working public holidays), little advanced warning of being required for duty, and waiting for job to start [29]. Other issues identified included the physical consequences of working long hours, and the reduction in quality of life [28]. In an investigation of job satisfaction, one article reported that worker satisfaction predicted employee turnover, such that dissatisfied pilots had greater intentions to leave their current role [40]. However, with the exception of Kaya Ozbag and Ceyhum's [40] findings, it remains unknown whether pilots low in job satisfaction have reduced well-being and shorter careers in pilotage.

\section{Marital or family conflict}

To date, much of the available evidence appraised the pilots' perceptions of well-being independent of other relationships. However, four investigations examined the relatedness between marital or family conflict and pilotage. Similar to the pilots' perceptions, results indicated that pilots' wives were dissatisfied with the irregular work hours, complained of disturbed sleep, had irregular meal-times, and experienced difficulty planning various social activities (e.g., holidays, appointments [29]). More recently, findings revealed that pilots who were married reported greater job satisfaction [28]. Furthermore, lower levels of family conflict predicted greater job satisfaction, while high levels of conflict predicted greater turnover [40]. However, two caveats of the aforementioned research were identified. First, the specific source of the conflict was unclear [40]. For example, it is plausible that a bi-directional relationship exists between family conflict and job satisfaction, thereby requiring further investigation. Second, only one article [26] explicitly assessed the role of social support provided by others to pilots. Given the physical and psychosocial demands of pilotage, an exploration of maritime pilots' social support and the impact on pilot well-being is required.

\section{Conclusions on psychosocial well-being factors}

The collective evidence on maritime pilot psychosocial well-being suggests that pilots are somewhat satisfied with the role, but experience stress as a consequence of pilotage. As was the case with the physiological evidence, there are several conclusions that can be drawn from the available well-being evidence.

First, the impact of stress on actual pilotage performance was not reported. Within the medical profession, the pressure to maintain optimal performance can increase stress, resulting in depression and the adoption of poor coping strategies [41]. Given that psychological stress can substantially impact one's ability to work, further investigation of the influence of stress on actual maritime pilotage performance is required to advance the field.

Second, in order to accurately measure and compare maritime pilotage stress within the maritime industry (e.g., seafarers) and between industries (e.g., aviation pilots), future research must again adopt standardised measures to facilitate subsequent comparison (e.g., the Perceived Stress Scale [42]).

Third, the lack of attention paid to mental health issues requires immediate attention. Elsewhere, it is reported that psychological dysfunction (e.g., anxiety, depression) as a consequence of occupational stress is a significant issue for individuals and organisations [43]. While pursuing this line of inquiry is imperative, a caveat to overcome is the challenging maritime context. Traditionally, expressing weakness is shunned in the maritime context, which may result in an under-reporting of factors such as emotional disturbance and mental health issues [29]. This cultural practice represents a potential hurdle for future research in this context. Collaborative agreements between research institutions and industry bodies will facilitate the generation of more meaningful and accurate evidence that lead to practical outcomes. Equally, anonymous data collection through online surveys may also facilitate this process.

\section{FACTORS ASSOCIATED WITH THE WORK ENVIRONMENT}

In sum, 7 work-related factors that contributed to the physical health and well-being of pilots emerged from the reviewed articles. Some of these factors included increased commercial pressures and variations in workplace training (e.g., shorter turn-around times [5]), the presence or absence of social activities for pilots [29], and work-related benefits and remuneration [28]. The most commonly cited work-related factor was the influence on the shift cycle and or duration on pilot health and well-being. 


\section{Shift duration and cycle}

The duration of pilotage shift-cycles was reported in 7 of the reviewed articles. In addition to the aforementioned fatigue experienced by pilots, these findings confirmed that the length of a job, and the shift cycle varied considerably $[6,22]$. For example, the average time to complete one pilotage passage varied from $2.5 \mathrm{~h}$ [29] to $39.5 \mathrm{~h}$ [7]. The demands of pilotage shift work are consistent with other occupations, including the medical profession. For example, doctors experience heavy workloads, comprised of long shift and unpredictable hours, which can result in psychological stress [41]. Given the diversity of pilotage requirements (e.g., differences in port requirements, vessel types) it is apparent that a standardised shift cycle or roster is unrealistic. However, future research could 1) explore improvements to ship-forecasting and working arrangements [29], 2) investigate the plausibility, and subsequent benefits of napping while on-shift $[8,28]$, and 3 ) assist in the examination of workplace policy on the impact of shift work on pilotage health and well-being [28]. A longitudinal analysis of shift-cycle on pilot health and well-being may also uncover further issues that could inform amendments to current practice.

\section{Physical work environment}

Three of the reviewed articles described the impact of the work environment on pilot health, with findings revealing that pilots often worked in unconducive operational environments (e.g., poor bridge quality [5]), which likely contributed to a number of workplace accidents, including those attributed to human error [8]. Given that pilots often complete long passages and shifts in such environments, it is crucial that more evidence be compiled on how these conditions impact pilots' long-term health and well-being. For example, two studies of maritime pilot workload, not captured in the current review process, demonstrated that exposure to unfavourable working conditions (e.g., pilot boat noise) significantly contributed to the health problems experienced by pilots, including sleep disturbance [44, 45].

\section{Conclusions on work environment factors}

The review of pilots' working environment revealed that the shift cycle and physical working conditions present as factors that may affect pilot health and wellbeing. In examining these factors, two main limitations were identified.

First, there was a lack of research investigating the impact of long-term exposure to these environmental work factors on physical health and psychosocial well-being. Evidence that uncovers the impact of these factors on pilots, and offers strategies to assist pilots in managing the challenges of the pilotage working environment are required. For example, of the 18 articles reviewed, only one cited training as a work-related factor that may positively impact health and well-being. Darbra et al. [5] reported that $71 \%$ of pilots had completed a bridge resource management course (BRM), yet no evidence was available that quantified the effectiveness of BRM on improving pilotage performance. Before such training is advocated globally, research is required to determine the extent to which BRM impacts the pilot's ability to execute his or her role (i.e., improve performance), and in doing so, cope with the aforementioned environmental work stressors.

Second, there was an absence of research examining the impact of modern bridge design and related technologies on pilot health and well-being as many of the reviewed studies are dated. For example, modern pilots have an array of electronic navigational tools to assist them during pilotage. What remains unknown is whether the implementation of these tools has an impact on physical health and or psychological well-being. Specifically, 1) whether contemporary pilots, who rely on electronic chart display and radar, are more sedentary on-shift if they are no longer required to move about the bridge to obtain best line of sight, and 2) whether the long-term demands associated with monitoring these dynamic displays and maintaining situation awareness for extended periods of time impairs pilot health and well-being.

\section{SUMMARY AND FUTURE RESEARCH DIRECTIONS}

The aim of this review was to examine the current empirical literature pertaining to the health and well-being of maritime pilots. While some informative industry reports were identified during the search for relevant research (e.g. [46]), the focus was on peer-reviewed research articles. Following standardised systematic review processes, a total of 18 articles were assessed for factors related to maritime pilots' physical health and psychological well-being. The review identified a number of methodologies adopted to examine pilot health and well-being (e.g., interviews, cross-sectional survey, and ambulatory assessment). Furthermore, the review revealed that there was an emphasis on physiological $(n=14)$ compared to psychosocial factors $(n=8)$. In addition to these factors, this review highlighted a number of work-related factors $(n=7)$ that influence pilot health and well-being. In sum, there appeared to be a strong preference for examining physiological factors of pilot health, with little field-based evidence available on pilot well-being.

It is clear that advancing the existing knowledge pertaining to maritime pilot health and well-being must be a priority, and needs to be supported by rigorous scientific investigation. A critical limitation of this paper is the quality of the reviewed research. The small and low level evidence studies included in our review should not be considered as 
compromising the standard of the review, nor a criticism of the existing research. For example, many of the 18 studies reviewed included small sample sizes that inhibited the generalisability of the findings. Rather, these studies reflect some of the challenges of researching in this context (e.g., participant recruitment) and a lack of awareness of the importance of the maritime pilot health and well-being. Therefore, the current study draws attention to the importance of pilots in the maritime industry, and highlights the need for further research in this highly specialised context. Hence, five recommendations are proposed to guide future investigations into maritime pilotage.

First, multidisciplinary approaches (e.g., physiology, psychology, and performance) should be adopted be researchers to generate more meaningful data on maritime pilots. Since the pioneering work of Cook and Shipley [6], there have been a number of developments within the maritime context that have increased the complexity of pilotage, thereby limiting the generalisability of these findings. For example, the increased reliance on technological navigational aids [47], coupled with rising commercial pressures [10], suggests that new evidence is required in order to better understand whether these changes impact pilot health and well-being. Adopting multidisciplinary approaches, supported by sufficiently powered sample sizes, will lead to an improved understanding of the impact of pilotage on long-term health and well-being. It is anticipated that such investigations will yield more meaningful data on the biopsychosocial associations inherent in health and well-being, which in turn may facilitate the development of viable strategies to tackle dysfunctional pilot health and well-being.

Second, researchers are encouraged to use relevant theoretical frameworks where appropriate to guide their investigative endeavours. The adoption of such frameworks will empower researchers to explore questions and test hypotheses with greater rigour. For example, one model that seems befitting of the maritime context is the job demand-control (-support) model (JDC [48, 49]). In adopting this model, researchers would be able to explore the strain hypothesis of the JCD model in relation to a variety of mental (e.g., life satisfaction, depression) and physical health (e. g., physical activity) outcomes [50].

Third, there is a disproportionate understanding of maritime pilot well-being compared to physical health that needs to be immediately addressed. While the reviewed articles contributed valuable knowledge towards pilot health, they generated scant knowledge of the psychological and social factors that impact upon pilots. For example, the lack of knowledge on pilot mental health (e.g., presence or absence of psychological dysfunction) is concerning, particularly given that the physical health evidence suggests these individuals are performing stressful tasks, and are at risk of CVD. Given that other highly specialised industries (e.g., medicine) have identified the link between occupational stress and various mental health issues (e.g., depression, anxiety [51]), such investigations need to be prioritised to advance maritime pilotage knowledge.

Fourth, intervention research that specifically targets maritime pilot health and well-being initiatives is required. It is clear that maritime pilots are a unique group of workers who are distinct from other maritime, and transportation personnel. For example, maritime pilots do not experience the same issues of isolation and limitations to recreation activities as seafarers [2], nor do they adopt similar fatigue coping strategies as aviation pilots [4]. Any interventions that target health and well-being related issues should therefore be sensitive to the contextual demands faced by maritime pilots. In doing so, these interventions should empower pilots to take responsibility for maintaining their health and well-being [29]. Specifically, evidence that demonstrates strategies to reduce exposure to known risk factors of CVD (e.g., smoking, obesity) and or mental health issues (e.g., anxiety, depression, and burnout), which leads to improved pilot health and optimal performance, is required.

Finally, a review of career and education practices for maritime pilots may yield greater insight into the movement of pilots into, and out of the occupation. For example, a contemporary review of working arrangements and shift rosters may reveal issues related to pilot workload and fatigue management that could influence pilot retention. Education on pilotage career pathways and alternative training methods (e.g., simulation) may be an area of further inquiry; as new educational pathways emerge and trainee pilots are fasttracked, an exploration of these vocational developments is required. Likewise, given the seemingly aging demographic of pilots, evidence-based strategies to recruit, train, and retain pilots is essential. In sum, intervention research on health and well-being initiatives for maritime pilots that are supported by multidisciplinary approaches will mark the next wave of investigative inquiry.

\section{DISCLAIMER}

It should be noted that the views of the authors expressed in the submitted article are their own and not an official position of either institution or funder.

\section{REFERENCES}

\section{(*Denotes that the article was included in the systematic review)}

1. Australian Maritime Safety Authority. Corporate plan 2015-2019;2015.

2. Carotenuto A, Molino I, Fasanaro AM, Amenta F. Psychological stress in seafarers: a review. Int Marit Health 2012; 63: 188-194.

3. Nielsen MB, Bergheim K, Eid J. Relationships between work environment factors and workers' well-being in the maritime industry. Int Marit Health 2013; 64: 80-88. 
4. *Chambers TP, Main LM. Symptoms of fatigue and coping strategies in maritime pilotage. Int Marit Health 2015; 66: 1-6.

5. *Darbra RM, Crawford JFE, Haley CW, Morrison RJ. Safety culture and hazard risk perception of Australian and New Zealand maritime pilots. Marine Policy 2007; 31: 736-745. doi: 10.1016/j. marpol.2007.02.004.

6. ${ }^{*}$ Cook T, Shipley P. Human factors studies of the working hours of UK ship's pilots 1. A field study of fatigue. Appl Ergon 1980; 11: 85-92.

7. *Ferguson SA, Lamond N, Kandelaaris K, Jay SM, Dawson D. The impact of short, irregular sleep opportunities at sea on the alertness of marine pilots working extended hours. Chrono Int 2008; 25: 399-411. doi: 10.1080/07420520802106819.

8. *Meere K, Van Damme J, Sprundel MV. Occupational injuries in Flemish pilots in Belgium A questionnaire survey. Int Marit Health 2005; 56: 1-4.

9. *Zorn EW, Harrington JM, Goethe H. Ischemic heart disease and work stress in West German sea pilots. J Occ Med 1977; 19: 762-765.

10. Hetherington C, Flin R, Mearns K. Safety in shipping: The human element. J Safety Res 2006; 37: 401-411. doi: 10.1016/j. jsr.2006.04.007.

11. Australian Transportation Safety Bureau. Australian shipping occurrence statistics 2005 to 2012; 2013.

12. Iversen RTB. The mental health of seafarers. Int Marit Health 2012; 63: 78-89.

13. Kingdom SE, Smith AP. Work-related stress in Her Majesty's Coastguard. Int Marit Health 2011; 62: 148-154.

14. Kingdom SE, Smith AP. Combined effect of work-related stress in Her Majesty's Coastguard (HMCG). Int Marit Health 2012; 63: 63-70.

15. Diener E, Chan MY. Happy people live longer: Subjective well-being contributes to health and longevity. App Psy: Health Well-being 2011; 3: 1-43. doi: 10.1111/j.1758-0854.2010.01045.x.

16. Lyubomirsky S, King L, Diener E. The benefits of frequent positive affect: does happiness lead to success? Psy Bull 2005; 131: 803-855. doi: 10.1037/0033-2909.131.6.803.

17. Allen $P$, Wadsworth $E$, Smith $A$. Seafarers' fatigue: a review of the recent literature. Int Marit Health 2008; 59: 81-92.

18. MacLachlan M, Kavanagh B, Kay A. Maritime health: a review with suggestions for research. Int Marit Health 2012; 63: 1-6.

19. Moher D, Liberati A, Tetzlaff J, Altman DG, PRISMA Group. Preferred reporting items for systematic reviews and metaanalyses: the PRISMA statement. BMJ 2009; 339: 25-35.

20. ${ }^{\star}$ Kim H, Yang CS, Lee BW, Yang YH, Hong S. Alcohol effects on navigational ability using ship handling simulator. Int J Indust Erg 2007; 37: 733-743.

21. *Van Damme J. Prevention of post-traumatic stress disorder amongst maritime pilots. Int Marit Health 2003; 54: 1-4.

22. *Cook TC, Cashman PMM. Stress and ecoptic beats in ships' pilots. J Psy Res 1982; 26: 559-569.

23. *Rutledge, P. A comparison of health data from River Forth pilots in Scotland: in 1988 and 2012. Int Marit Health 2014; 65: 43-46.

24. *Scovill SM, Roberts TK, McCarty DJ. Health characteristics of inland waterway merchant marine captains and pilots. Occup Med 2012; 62: 638-641.

25. *Saarni H, Niemi L, Pentti J, Hartiala J, Kuusela A. Cardiac status and cardiovascular risk factors among Finnish sea pilots. Int J Occ Med Env Health 1996; 9: 53-58.

26. ${ }^{\star}$ Sparks PJ. Questionnaire survey of masters, mates, and pilots of a state ferries system on health, social and performance indices relevant to shift work. Am J Ind Med 1992; 21: 507-516.
27. Pachman J. Evidence base for pre-employment medical screening. Bull World Health Organ 2009; 87: 529-534. doi: 10.2471/ BLT.08.052605.

28. *Andresen M, Domsch ME, Cascorbi AH. Working unusual hours and its relationship to job satisfaction: a study of European maritime pilots. J Lab Res 2007; 28: 714-734. doi: 10.1007/s12122-0079010-5.

29. *Shipley P, Cook TC. Human factors studies of the working hours of UK ships' pilots. Part 2: A survey of work-scheduling problems and their social consequences. Appl Ergon 1980; 11:151-159.

30. Åkerstedt T, Wright, KP. Sleep loss and fatigue in shift work and shift work disorder. Sleep Med Clin 2009; 4: 257-271. doi:10.1016/j. jsmc.2009.03.001.

31. Johns MW. A new method for measuring daytime sleepiness: the Epworth sleepiness scale. Sleep 1991; 14: 540-545.

32. Buysse DJ, Reynolds CF, Monk TH, Berman SR, Kupfer DJ. The Pittsburgh Sleep Quality Index (PSQI): A new instrument for psychiatric research and practice. Psy Res 1989; 28: 193-213.

33. Gander P, Hartley L, Powell D et al. Fatigue risk management: Organizational factors at the regulatory and industry/company level. Acc An Prev 2011; 43: 573-590. doi: 10.1016/j.aap.2009.11.007.

34. Pink B. Overweight and obesity in adults in Australia: a snapshot. Australian Bureau of Statistics; 2011.

35. * Saarni H, Niemi L, Koskela R-S, Pentti J, Kuusela A. Mortality among Finnish sea pilots 1956-1985: a retrospective cohort study. Occup Med 1996; 46: 281-284.

36. Hjarnoe L, Leppin A. Health promotion in the Danish maritime setting: challenges and possibilities for changing lifestyle behavior and health among seafarers. BMC Pub Health 2013; 13: 1165-1177.

37. Jeżewska M, Jaremin B, Leszczyńska I. Health promotion in the maritime work environment: training of leaders. Int Mar Health 2007; 58: 1-4.

38. van Drongelen A, van der Beek AJ, Hlobil H, Smid T, Boot CRL. Development and evaluation of an intervention aiming to reduce fatigue in airline pilots: design of a randomised controlled trial. BMC Pub Health 2013: 13: 776-785. Retrieved from http://www. biomedcentral.com/1471-2458/13/776.

39. * Griffiths RF, Ellis PM. Visual conversion disorder in a harbor pilot leading to sudden loss of control of a large vessel. Aviat Space Environ Med 2007; 78: 59-62.

40. *Kaya Ozbag G, Ceyhum GC. Does job satisfaction mediate the relationship between work-family conflict and turnover? A Study of Turkish Marine Pilots. Procedia-Soc Behav Sci 2014; 140: 643-649. doi: 10.1016/j.sbspro.2014.04.485.

41. Brooks SK, Gerada C, Chalder T. Review of literature on the mental health of doctors: Are specialise services needed? J Ment Health 2011; 62: 1-11.

42. Cohen S, Kamarck T, Mermelstein R. A global measure of perceived stress. J Health Social Behav 1983; 24: 386-396.

43. Mark G, Smith AP. Occupational stress, job characteristics, coping, and the mental health of nurses. B J Health Psy 2012; 17: 505-521. doi: 10.1111/j.2044-8287.2011.02051.x.

44. de Vries GM, Vries-Griever ARG. Sleep problems and state of health: a replication of the effects of abnormal, irregular and condensed working hours. In: Costa G, Cesana G, Kogi K, Wedderburn A (eds). Shiftwork, Health, Sleep and Performance. Peter Lang, Frankfurt am Main, Germany 1990a, pp. 370-375.

45. de Vries GM, Vries-Griever ARG. The process, of developing health complaints: a longitudinal study of the effects of abnormal, irregular and condensed working hours. In: Costa G, Cesana G, Kogi K, 
Wedderburn A (eds). Shiftwork, Health, Sleep and Performance. Peter Lang, Frankfurt am Main, Germany 1990b, pp. 290-296.

46. Parker AW, Briggs J, Hubinger LM, Folkard S, Green S. The work practices of marine pilots: A review. 1998. Available from http:// www.amsa.gov.au/Shipping_Safety/Coastal_Pilotage/Fatigue_study_on_Coastal_Pilots/The_work_practices_of_Marine_Pilots/.

47. Saus ER, Johnsen BH, Eid J, Thayer JF. Who benefits from simulator training: Personality and heart rate variability in relation to situation awareness during navigation training. Comp Human Behav 2012; 28: 1262-1268.

48. Johnson JV, Hall EM, Theorell T. Combined effects of job strain and social isolation on cardiovascular disease morbidity and mortality in a random sample of the Swedish male working population. Scand Work, Enviro Health 1989; 15: 271279.

49. Karasek RA. Job demands, job decision latitude, and mental strain: Implications for job redesign. Admin Sci Quart 1979; 24: 285-308.

50. Van der Doef M, Maes S. The Job Demand-Control-(Support) model and psychological well-being: a review of 20 years of empirical research. Work Stress 1990; 13: 87-114.

51. van der Ploeg E, Dorresteijn SM, Kleber RJ. Critical incidents and chronic stressors at work: their impact on forensic doctors. J Occ Health Psych 2003; 8: 157-166. doi: 10.1037/10768998.8.2.157. 